\title{
Surgical management of astigmatism with toric intraocular lenses
}

\author{
Uso de lentes intraoculares tóricas no tratamento cirúrgico de astigmatismo
}

Bruna V. Ventura ${ }^{1,2,3}$, LI Wang ${ }^{1}$, Mitchell P. Weikert ${ }^{1}$, Shaun B. Robinson ${ }^{1}$, Douglas D. Koch ${ }^{1}$

\begin{abstract}
Correction of corneal astigmatism is a key element of cataract surgery, since post-surgical residual astigmatism can compromise the patient's uncorrected visual acuity. Toric intraocular lenses (IOLs) compensate for corneal astigmatism at the time of surgery, correcting ocular astigmatism. They are a predictable treatment. However, accurate measurement of corneal astigmatism is mandatory for choosing the correct toric IOL power and for planning optimal alignment. When calculating the power of toric IOLs, it is important to consider anterior and posterior corneal astigmatism, along with the surgically induced astigmatism. Accurate toric lens alignment along the calculated meridian is also crucial to achieve effective astigmatism correction. There are several techniques to guide IOL alignment, including the traditional manual marking technique and automated systems based on anatomic and topographic landmarks. The aim of this review is to provide an overview on astigmatism management with toric IOLs, including relevant patient selection criteria, corneal astigmatism measurement, toric IOL power calculation, toric IOL alignment, clinical outcomes and complications.
\end{abstract}

Keywords: Astigmatism; Toric intraocular lenses; Refractive errors; Corneal topography; Complications

\section{RESUMO}

O tratamento do astigmatismo corneal é um fator importante na cirurgia de catarata, uma vez que o astigmatismo residual pode comprometer a acuidade visual não corrigida do paciente após a cirurgia. Lentes intraoculares (LIOs) tóricas compensam o astigmatismo corneal no momento da cirurgia, corrigindo o astigmatismo ocular. Ademais, constituem um tratamento previsível. Entretanto, é necessário obter uma medida precisa do astigmatismo corneal para selecionar o poder correto da LIO tórica e para planejar o melhor alinhamento da mesma. No cálculo do poder da LIO tórica, é importante considerar o astigmatismo das superfícies anterior e posterior da córnea, além do astigmatismo induzido na cirurgia. O alinhamento da lente tórica no meridiano planejado é essencial para se obter uma correção efetiva do astigmatismo. Há várias técnicas para guiar o alinhamento da LIO, incluindo a técnica de marcação manual tradicional e sistemas que se baseiam em pontos de referência anatômicos e topográficos. O objetivo desse artigo de revisão é discutir o uso de LIOs tóricas no tratamento de astigmatismo corneal, incluindo os critérios de seleção dos pacientes, a medida do astigmatismo corneal, o cálculo do poder da LIO tórica, o alinhamento da LIO tórica, os resultados clínicos e as complicações.

Descritores: Astigmatismo; Implante de lente intraocular; Planejamento cirúrgico; Topografia da córnea; Complicações

\section{INTRODUCTION}

In the last 3 decades, advances in cataract surgery have dramatically improved patients' outcomes, increasing expectations regarding visual results. Simultaneously, some key factors associated with good visual outcomes were identified. It has been estimated that $30 \%$ of cataract patients have more than 0.75 diopters (D) of corneal astigmatism, that $22 \%$ have more than $1.50 \mathrm{D}$, and that $8 \%$ have more than $2.00 \mathrm{D}^{(1,2)}$. Since post-surgical residual astigmatism can compromise uncorrected distance visual acuity (UDVA), correction of corneal astigmatism is a critical element of modern cataract surgery.

Corneal astigmatism can be surgically treated with adjustment of wound size and location, peripheral corneal relaxing incisions, additional clear corneal cataract incision along the steep meridian, laser refractive surgery, or toric intraocular lenses (IOLs). Toric IOLs correct corneal astigmatism at the time of cataract surgery and are a predictable treatment in general|(3-18). Monofocal toric IOLs can be used to correct the patient's vision for distance, for near or for both (this latter being attained via monovision)(3-10), while multifocal toric IOLs aim at providing good uncorrected vision for near, intermediate and $\operatorname{far}^{(14-16,19)}$. Moreover, toric phakic IOLs are a largely reversible treatment option for pre-cataractous patients who are not good candidates for corneal refractive surgery and have clinically significant astigmatism ${ }^{(20-22)}$.
The final visual outcomes attained with toric IOLs depend on several factors, including the visual potential of the eye. The ideal patients for toric IOL implantation are those with regular astigmatism, although previous papers have also shown good outcomes in cases of stable, mild central irregular astigmatism, such as patients with mild to moderate stable keratoconus ${ }^{(23)}$, pellucid marginal degeneration ${ }^{(24)}$ and post-corneal transplant ${ }^{(25)}$. In these cases, it is important to have a fairly symmetrical power and alignment of the astigmatism within the cornea's central $4 \mathrm{~mm}$. Toric phakic IOLs can be used in adults and in children. Although there is no consensus regarding the use of toric phakic IOLs in children, many authors consider implanting them in patients with high anisometropia or high isometropia with an astigmatic component, and in those with neurobehavioral disorders and visually significant astigmatism. In these cases, the $\mathrm{IOL}$ is usually considered as a treatment option when the patient is non-compliant to medical treatment, including spectacles and contact lenses ${ }^{(20,21)}$. Multifocal toric lenses should be considered in patients who want good near and distance uncorrected visual acuity postoperatively and who have approximately $0.50 \mathrm{D}$ of corneal astigmatism or more ${ }^{(19,26)}$.

Toric IOLs should be avoided in patients with corneal dystrophies that might need a corneal transplant in the future and should be used with caution in patients with potential capsular bag instability. Phakic

Submitted for publication: January 17, 2014

Accepted for publication: March 13, 2014

Department of Ophthalmology, Cullen Eye Institute, Baylor College of Medicine, Houston, Texas, United States of America.

2 Fundação Altino Ventura, Recife, PE, Brazil.

${ }^{3}$ Department of Ophthalmology, Universidade Federal de São Paulo, São Paulo, SP, Brazil.

Funding: This study was supported by Research to Prevent Blindness.

Disclosure of potential conflicts of interest: B.V.Ventura, None; L.Wang, Consultant of Ziemer; M.P.Weikert, Consultant for Ziemer; S.B.Robinson, None; D.R.Koch, Consultant for Ziemer, AMO, Alcon and I-Optics.

Corresponding author: Bruna Vieira Ventura. Fundação Altino Ventura. Rua da Soledade, 170 Recife (PE) - 50070-040 - Brazil - E-mail: brunaventuramd@gmail.com 
toric IOLs should not be implanted in eyes with shallow anterior chambers and low endothelial cell counts ${ }^{(22)}$. In addition, as multifocal toric IOLs split the available light between the distance and near foci, they should not be implanted in patients with ocular comorbidities that affect the visual acuity or the quality of vision, such as amblyopia, maculopathy, glaucoma, and uveitis (27).

\section{Measuring corneal astigmatism and Calculating toric IOLs Devices}

The anterior and posterior corneal surfaces contribute to the total corneal astigmatism. Accurate measurement of corneal astigmatism is mandatory for choosing toric IOL power and planning optimal alignment. Various measuring methods are available, including manual keratometry, automated keratometry, corneal topography, slit-scanning technology, optical coherence tomography, and Scheimpflug imaging. The first three methods measure the anterior corneal surface only. Using a standardized corneal refractive index, most commonly 1.3375, they assume a fixed posterior:anterior corneal curvature ratio to calculate total corneal power and astigmatism. On the other hand, slit-scanning technology, optical coherence tomography and Scheimpflug imaging measure the anterior and posterior corneal surface. Therefore, they provide total corneal power and astigmatism based on the measured anterior and posterior corneal data.

No single method has been identified as being the best for measuring corneal astigmatism. Previous studies have shown that manual keratometry, automated keratometry, simulated keratometry of Placido-based corneal topography, and simulated keratometry of Scheimpflug imaging provide similar values for anterior corneal curvature ${ }^{(28-30)}$, although significant disagreement in axis location has been reported ${ }^{(29)}$. Contrarily, anterior corneal astigmatism measurements differed significantly when comparing values derived from total corneal power and equivalent keratometry to that of automated, manual, and simulated keratometry ${ }^{(30,31)}$. These three later measurements are based only on the anterior corneal surface data, while the total corneal power and equivalent keratometry are based on the measurements of both the anterior and posterior corneal curvatures. Total corneal power is calculated by tracking the path of incident light rays through the anterior and posterior corneal surface using a ray-tracing method and Snell's law with the true refractive indices to calculate the anterior and posterior corneal powers (1.376 for cornea and 1.336 for aqueous) $)^{(32)}$.

\section{The role of the posterior cornea}

Recent studies ${ }^{(15-17)}$ have shown the importance of considering the posterior corneal surface when determining total corneal astigmatism and planning astigmatism correction. The posterior cornea acts as a minus lens. It generally has a steeper vertical meridian, and remains steeper vertically with increasing age. The anterior corneal steeper meridian is also commonly oriented vertically in younger individuals, but shifts towards the horizontal meridian as patients get older. Thus, in general, posterior corneal astigmatism partially compensates for anterior corneal astigmatism in young adults and increases total corneal astigmatism in older individuals ${ }^{(33)}$.

The mean magnitude of posterior corneal astigmatism is $-0.30 \mathrm{D}$. Koch et al. ${ }^{(33)}$ have shown that one cannot accurately predict the posterior corneal astigmatism based only on anterior corneal measurements. They found maximal values of posterior corneal astigmatism of over $0.8 \mathrm{D}$ in corneas that had with-the-rule astigmatism on the anterior corneal surface and of over $0.5 \mathrm{D}$ in corneas that had against-the-rule corneal astigmatism on the anterior corneal surface. The correlation between anterior and posterior corneal astigmatism was moderate when the steep anterior meridian was aligned vertically, weak when it was oriented obliquely, and absent when it was aligned horizontally ${ }^{(33)}$.
A second study by Koch et al. ${ }^{(35)}$ reported in pseudophakic eyes the mean corneal astigmatism prediction error of four devices that calculate total corneal astigmatism based only on anterior surface measurements. The corneal astigmatism prediction error (the deviation from the actual total corneal astigmatism) was obtained by subtracting the actual corneal astigmatism (which is the difference between the postoperative manifest refraction corrected to the corneal plane and the effective toric IOL power calculated with the Holladay IOL Consultant Program (Holladay Consulting, Inc., Bell Air, USA) from the corneal astigmatism measured by each device. Their results confirmed the findings in the above-noted study. They found an overestimation of with-the-rule astigmatism of 1) 0.5 to $0.6 \mathrm{D}$ in eyes that had with-the-rule astigmatism on the anterior corneal surface and 2) 0.2 to $0.3 \mathrm{D}$ in eyes that had against-the-rule corneal astigmatism on the anterior corneal surface. Posterior corneal astigmatism can be measured directly using devices such as the dual Scheimpflug analyzer, although the accuracy on an individual basis is still uncertain. Alternatively, one can account for posterior corneal astigmatism using nomograms such as the Baylor Toric IOL Nomogram (Table 1). Although this nomogram derived from the findings of previous studies ${ }^{(33,35)}$, further validation would be beneficial.

\section{Surgically induced astigmatism}

When calculating the power of toric IOLs, it is also important to consider the surgically induced astigmatism (SIA). The SIA is a result of flattening in the meridian of incision and steepening $90^{\circ}$ away ${ }^{(36)}$. The amount of SIA depends on several factors, including the size, shape, and location of the incision, suture use, and the response of the patient's cornea. As an incision is placed further from the optical axis, it may progressively have a bigger width and still remain astigmatically neutral. Thus, a longer scleral tunnel incision can induce as much SIA as a shorter clear corneal incision ${ }^{(37)}$. With regards to shape of the scleral tunnel incision, various authors have investigated the SIA associated with straight, curved (parallel to the limbus), reverse curved (frown incision), and V-shaped incisions. However, none of these shapes have been clearly shown to induce less astigmatism ${ }^{(38,39)}$. Conversely, previous papers have shown that incision location plays an important role in the amount of SIA. Nasal, superonasal and superior incisions induce more astigmatism than temporal and superotemporal incisions ${ }^{(40-43)}$. Each surgeon should calculate his/her own SIA, which can be done using a standard astigmatism vector analysis ${ }^{(44)}$. One of the websites that can be used for this purpose is http://www.doctor-hill.com/(45).

\section{Table 1. Baylor Toric IOL Nomogram* (postoperative target: up to 0.40 D} WTR astigmatism)

\begin{tabular}{|c|c|c|}
\hline $\begin{array}{l}\text { Effective IOL cylinder power at } \\
\text { corneal plane (D) }\end{array}$ & WTR (D) & ATR (D) \\
\hline 0 & $\leq 1.69(P C R \mid$ if $>1.00)$ & $<0.39$ \\
\hline 1.00 & $1.70-2.19$ & $0.40^{*}-0.79$ \\
\hline 1.50 & $2.20-2.69$ & $0.80-1.29$ \\
\hline 2.00 & $2.70-3.19$ & $1.30-1.79$ \\
\hline 2.50 & $3.20-3.69$ & $1.80-2.29$ \\
\hline 3.00 & $3.70-4.19$ & $2.30-2.79$ \\
\hline 3.50 & $4.20-4.69$ & $2.80-3.29$ \\
\hline 4.00 & $4.70-5.19$ & $3.30-3.79$ \\
\hline \multicolumn{3}{|c|}{$\begin{array}{l}\text { WTR }=\text { with-the-rule astigmatism; ATR= against-the-rule astigmatism; } D=\text { diopter; } \\
P C R I=\text { peripheral corneal relaxing incision. } \\
{ }^{*}=\text { values in the table are the vector sum of the anterior corneal and surgically induced } \\
\text { astigmatism If an } S N 6 A T 2 \text { is available, consider implanting it in WTR astigmatism of } \\
1.40-1.69 \mathrm{D} \text {, and in ATR of } 0.30-0.49 \mathrm{D} \text { (in this latter case, T3 would be implanted in } \\
\text { astigmatism ranging from } 0.50 \text { to } 0.79 \mathrm{D} \text { ). }\end{array}$} \\
\hline
\end{tabular}




\section{Calculating toric IOL power}

Determination of the optimal IOL toricity can be performed using a calculation program provided by the manufacturer, calculation methods described in the literature ${ }^{(46)}$, or nomograms, such as the Baylor Toric IOL Nomogram (Table 1). The cylindrical power of the toric IOL should be chosen based on the total corneal astigmatism, taking into consideration anterior corneal astigmatism, posterior corneal astigmatism, and SIA. Another factor to consider is the impact of effective lens position and of the spheroequivalent power of the IOL on the effective cylinder power of the IOL at the corneal plane. Effective toricity of the $\mathrm{IOL}$ diminishes with increasing anterior chamber depth and lower IOL spherical power. The Holladay IOL Consultant Program and the Tecnis Toric Calculator (Abbott Laboratories Inc., Santa Ana, USA ${ }^{(47)}$ take this into account in its calculation of toric IOL power. Furthermore, when choosing the IOL toricity, it is desirable to leave patients with slight with-the-rule astigmatism, due to the normal tendency for astigmatism to drift against-the-rule with advancing age. Thus, leaving this slight with-the-rule astigmatism prolongs the period of time in which the patient's corneal astigmatism is compensated by the toric $\mathrm{IOL}^{(15,23,33,48)}$.

\section{TORIC IOL ALIGNMENT AND EYE MARKING TECHNIQUES}

During surgery, the marks on the toric $\mathrm{IOL}$ should be aligned with the previously marked meridian of alignment. The marks on the IOL indicate the flat meridian (plus cylinder axis) of the toric lens. Accurate toric lens alignment at the calculated meridian is crucial to achieve effective astigmatism correction. When a toric $\mathrm{IOL}$ is misaligned, there is a reduction in the cylinder correction along the desired meridian and induction of cylinder at a new meridian. For any given eye, the magnitude of residual cylinder power and the site of the new cylinder axis depend on the cylinder power of the toric IOL and the degree of misalignment. The precise relation between residual cylinder and meridional misalignment is sinusoidal, although, within 15 degrees of misalignment, the amount of residual cylinder is approximately $3.5 \%$ per degree. A $30^{\circ}$ misalignment induces an estimated residual cylinder of $100 \%$ of the toric IOL cylinder power, again with the new astigmatic meridian far away from the original steep meridian ${ }^{(49)}$. Importantly, the residual cylinder can be large and visually disturbing to the patient.

Preoperatively, the eye should be marked with the patient in an upright position to compensate for cyclotorsion. When the patient goes from the upright to the supine position, a cyclotorsion of approximately $2^{\circ}$ to $3^{\circ}$ usually occurs, with some patients having up to $14^{\circ}$ of cyclotorsion ${ }^{(50,51)}$. Also, the marking procedure should be performed with the patient fixating with the contralateral eye at a distant target at head height to avoid cyclotorsion from near-fixation.

There are several eye marking techniques. The most commonly described is a 3-step procedure: 1) preoperatively marking the eye at the horizontal meridian, which can be done using a coaxial thin slit beam of the slit-lamp turned to the 3-and 9-o'clock position, a bubble marker, a pendular marker, or a tonometer marker, (2) intraoperatively aligning to these marks a secondary device with angular graduations, such as the Mendez gauge, and (3) then marking the limbus or the cornea at the desired angle of alignment using a surgical marking pen or a needle ${ }^{(49,52)}$. A previous study evaluating the accuracy of the 3-step procedure using a bubble marker in the first step found a mean error in axis marking of $2.4^{\circ} \pm 0.8^{\circ}$, and a total error in toric $\mathrm{IOL}$ alignment of $4.9^{\circ} \pm 2.1^{\circ}$. Even though the slit-lamp marker and the pendular marker seem to be more accurate than the bubble marker and the tonometer marker ${ }^{(52)}$, the eye marking procedure is a potential source of error for toric IOL alignment, and should be done carefully, independently of the instruments used.

A 1-step technique has been described using a slit-lamp eyepiece with an embedded angle-measuring reticule or using a slit-lamp that allows measurement of the angle in which the slit beam is rotated ${ }^{(49)}$.
Another technique uses a preoperative anterior segment photograph of the cornea and limbal vessels together with imaging software to determine the distance from two reference limbal vessels to the desired alignment meridian ${ }^{(53)}$. Intraoperatively, the surgeon uses calipers to apply the distances calculated from the photograph to the reference vessels and to mark the desired meridian for IOL alignment. This later technique had a mean meridional marking error of $2.29^{\circ} \pm 1.06^{\circ(53)}$.

An iris fingerprinting technique is another option for marking the eye ${ }^{(54)}$. A preoperative detailed image of the eye is obtained, the desired alignment meridian is drawn, and the image is printed and used in the operating room to align the toric lens based on iris characteristics.

Several imaging modalities for toric IOL alignment have been developed, including the Callisto Eye with Z-Align (Carl Zeiss Meditec AG, Jena, Germany), the iTrace with Zaldivar Toric Caliper (Tracey Technologies, Houston, USA), the TrueGuide software (TrueVision 3D Surgical, Inc., Santa Barbara, USA), and the VERION Digital Marker (Alcon Laboratories, Ft. Worth, USA).

Zeiss' Callisto Eye with Z-align integrates with the OPMI Lumera 700 microscope (Carl Zeiss Meditec AG, Jena, Germany) and overlays graphical data onto real-time video images in the operating room. The original version requires preoperative manual marking of the $0^{\circ}$ and $180^{\circ}$ axis with the patient seated. The horizontal axis serves as a reference axis, being automatically detected by the Callisto system intraoperatively. Using this reference axis, the intended toric IOL axis (entered into the Callisto interface preoperatively) is digitally displayed to the surgeon as three parallel lines superimposed on the patient's eye within the oculars of the operative microscope. Active eye tracking software using the inkpen marks and software recognition of the limbus maintains alignment of the digitally overlaid axis lines with the position of the eye in real-time. This graphical overlay serves as a visible guide to the surgeon for toric IOL alignment along the appropriate axis. A newer version of Callisto Eye is available; this imports a high contrast digital reference image obtained by the IOLMaster 500 biometer (Carl Zeiss Meditec., Jena, Germany) to determine the reference axis and provide intraoperative eye-tracking, based on limbal and scleral vessels $s^{(55)}$.

Tracey's iTrace preoperatively measures the patient's corneal topography and keratometry, displaying the corneal topography data and a reticule superimposed on a photograph of the patient's cornea and limbus (Figure 1). The Zaldivar Toric Caliper tool can be used to calculate the angle difference in degrees between the steep meridian (intended toric IOL axis) and iris or limbal landmarks, both nasally and temporally. This information is printed and taken to the operating room for intraoperative guidance during toric $\mathrm{IOL}$ alignment (Figure 1).

The TrueGuide software uses a preoperative photograph and intraoperative registration to enable digital intraoperative surgical guidance and alignment of toric IOLs, without the need for preoperative ocular marking. The i-Optics Cassini topographer (i-Optics, The Hague, Netherlands) is used to obtain a high-resolution image of the patient's eye preoperatively (Figure 2). This source image is then uploaded to the TrueVision system in the operating room for intraoperative registration of the patient's eye based on iris landmarks, scleral/limbal vessels, and scleral pigmentation. When combined with the system's active tracking software, the intended toric $\mathrm{IOL}$ axis and a protractor along the limbus can be digitally aligned on a live view of the eye and tracked in real-time on a HD monitor to aid in $\mathrm{IOL}$ alignment.

Alcon's VERION Digital Marker also uses a high-resolution preoperative image and intraoperative registration to guide toric $\mathrm{IOL}$ alignment without the need of preoperative ocular marking. The VERION system matches the preoperative photograph with the eye intraoperatively using scleral vessels, limbal vessels, and iris features. This facilitates proper reference alignment and tracking of the eye in real-time throughout the case. The intended toric IOL axis along 


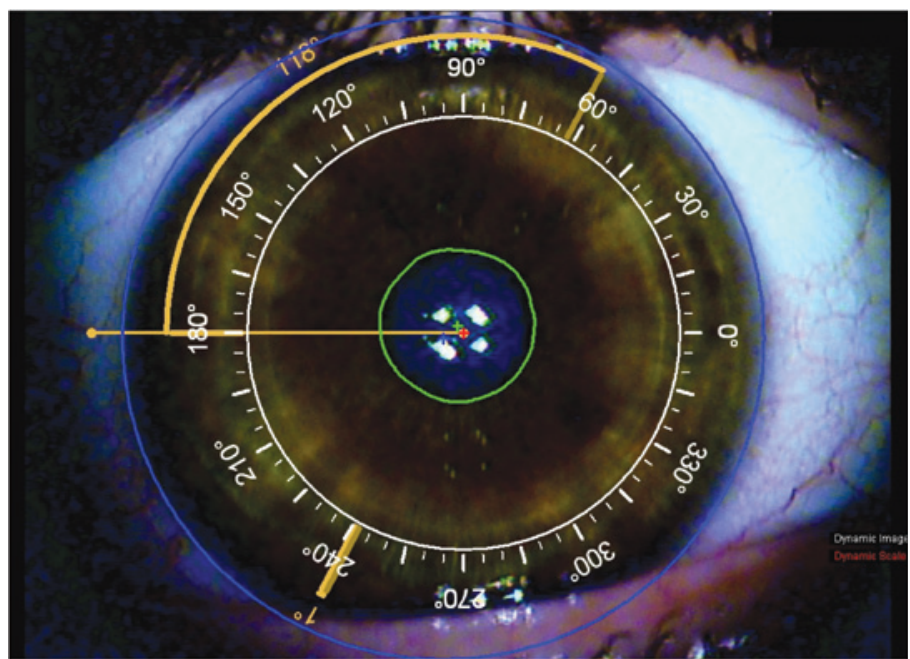

Figure 1. Image from iTrace to guide intraocular (IOL) lens alignment in a patient's right eye. A reticule is superimposed on a photograph of the patient's cornea and limbus. In this case the IOL should be aligned at $62^{\circ}$. The Zaldivar Toric Caliper tool is used to calculate the angle difference in degrees between the intended meridian for toric IOL alignment and a limbal vessel temporally $\left(118^{\circ}\right)$. This image is printed and used intraoperatively to guide IOL alignment.

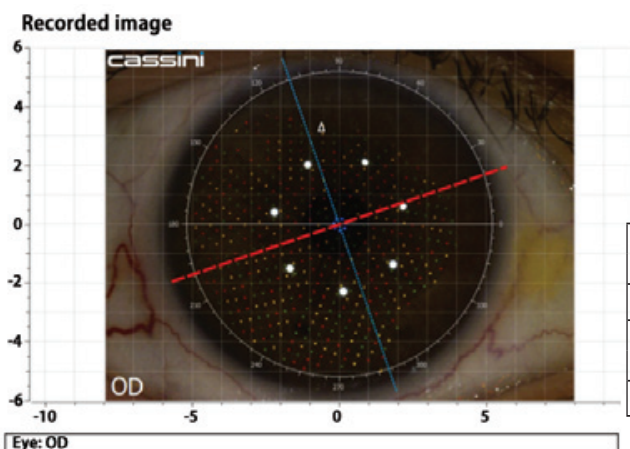

A
TrueUSB volume ID: TRUEUSB0320

Patient name:

Surgeon time:

Creation time: 2013-11-06 23:02

Last edited time: 2013-11-06 23:02

\begin{tabular}{|c|c|c|c|c|c|c|c|}
\hline $\begin{array}{l}\text { Age } \\
\text { (yrs) }\end{array}$ & Eye & $\begin{array}{l}\text { Flat K } \\
\text { (D) }\end{array}$ & $\begin{array}{l}\text { Steep K } \\
\text { (D) }\end{array}$ & $\begin{array}{c}\text { Steep } \\
\text { axis (deg) }\end{array}$ & $\begin{array}{l}\text { White to } \\
\text { white }(\mathrm{mm})\end{array}$ & $\begin{array}{c}\text { Pachymetry } 1 \\
(\mu \mathrm{m})\end{array}$ & $\begin{array}{c}\text { Pachymetry } 2 \\
(\mu \mathrm{m})\end{array}$ \\
\hline 69 & Right (OD) & 45.45 & 46.31 & 19.00 & 11.22 & 0 & 0 \\
\hline $\begin{array}{l}\text { Incision axis } \\
\text { (deg) }\end{array}$ & $\begin{array}{c}\text { Paracentesis } 1 \\
\text { (deg) }\end{array}$ & $\begin{array}{c}\text { Paracentesis } 2 \\
\text { (deg) }\end{array}$ & $\begin{array}{l}\text { IOL cylinder } \\
\text { (D) }\end{array}$ & $\begin{array}{c}\text { Toric axis } \\
\text { (deg) }\end{array}$ & $\begin{array}{l}\text { LRI arc length } \\
\text { (deg) }\end{array}$ & $\begin{array}{l}\text { LRI axis } \\
\text { (deg) }\end{array}$ & $\begin{array}{l}\text { LRI diameter } \\
\qquad(\mathrm{mm})\end{array}$ \\
\hline 172.00 & 112.00 & 232.00 & $0.69 \mathrm{D}(\mathrm{ZCT} 100)$ & 37.00 & 0 & 37.00 & 10.10 \\
\hline
\end{tabular}

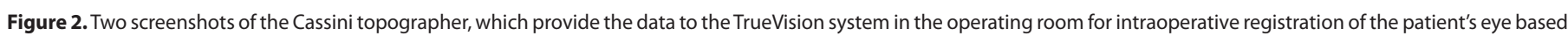

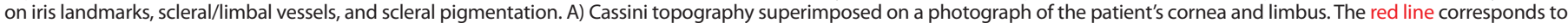

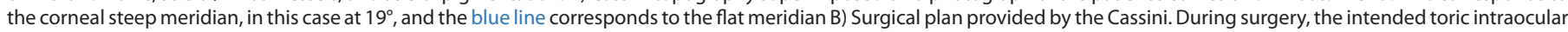
lens axis of alignment is digitally superimposed on the patient's eye in real-time.

with a limbal protractor is graphically aligned on a live view of the eye, being displayed on an external monitor or through the oculars of compatible microscopes. The toric IOL can then be aligned along the appropriate axis, guided by the digital overlay (Figure 3).

All of these automated systems using anatomic or topographic landmarks to guide toric IOL alignment seek to decrease the inherent error associated with preoperative manual marking alone. However, there is still a need for clinical studies to assess the efficacy of each of these systems.

\section{Clinical outcomes}

The correction of less than $0.50 \mathrm{D}$ of corneal astigmatism does not seem to improve visual performance ${ }^{(56)}$. However, in patients with corneal astigmatism above $0.75 \mathrm{D}$, implantation of toric IOLs is associated with better visual outcomes than monofocal IOLs: significantly more patients achieve an UDVA better than 20/40 and better than 20/25, are spectacle-independent, and have a lower absolute residual refractive cylinder ${ }^{(3)}$. In peer-reviewed papers, the reported percentage of patients achieving an UDVA better than 20/40 after toric IOL implantation ranges from $70 \%$ to $100 \%(4,5,32,33)$. Spectacle-independence for distance vision was reported by $60 \%$ to $85 \%$ of patients with unilateral toric $1 \mathrm{OL}(3,6,3,34)$ and by $69 \%$ to $97 \%$ of patients with bilateral toric IOLs ${ }^{(7,8,35,36)}$. Reported percentages of patients with residual refractive astigmatism lower than $0.50 \mathrm{D}$ range from $25 \%$ to $100 \%(9,10,37,38)$. In addition, patients with forme fruste keratoconus and mild non-progressive keratoconus generally have a meaningful reduction in ocular astigmatism and improved uncorrected visual acuity after toric IOL implantation ${ }^{(11-13)}$.

Toric multifocal IOLs are also associated with good visual outcomes. In the literature, an UDVA better than 20/40 has been reported in $97 \%$ to $100 \%$ of patients, while $100 \%$ of patients had an uncorrected near visual acuity better than $20 / 40^{(14,15,42,43)}$. Spectacle-independence was achieved by $79 \%$ to $100 \%$ of patients $s^{(15,16,43,44)}$. The percentage of patients with a residual refractive astigmatism lower than $0.50 \mathrm{D}$ ranged from $38 \%$ to $79 \%{ }^{(15,16)}$. However, some patients had symptoms that are typically associated with multifocal lenses, such as glare and halos ${ }^{(16)}$. Thus, when considering the implantation of a toric multifocal $\mathrm{IOL}$, it is important to explain to the patient the possible benefits, but also the potential of having disturbing visual symptoms inherent to the current models of multifocal IOLs. 
Previous studies have shown the efficacy, predictability, safety and stability of toric phakic IOLs in adults ${ }^{(17,18,36,45,46)}$. In a series of 42 eyes, Muñoz et al. ${ }^{(17)}$ reported that $78.6 \%$ of eyes had UDVA of $20 / 25$ or better one year after surgery, equal to the percentage of eyes with a CDVA of $20 / 25$ or better preoperatively. Seventy to $81 \%$ of eyes with toric phakic IOLs achieved a spherical equivalent within $\pm 0.50 \mathrm{D}$ range of the preoperative target, and $93 \%$ to $99 \%$ attained a spherical equivalent within $\pm 1.00 \mathrm{D}$ range ${ }^{(17,18,45,46)}$. There are no large prospective clinical studies of toric phakic lens implantation in patients with neurobehavioral disorders or in children with high anisometropia or high isometropia and a significant astigmatic component. However, published current case series have reported encouraging results, with a clinically significant decrease in spherical equivalent and improvement in visual acuity and vision-related quality of life ${ }^{(20,21)}$.

\section{Complications}

Toric lens misalignment is a concern, because the lens alignment is intrinsically related to its efficacy in correcting corneal astigmatism. Postoperatively, IOL misalignment from its intended position can be assessed using a slit-lamp with a rotating slit and rotational gauge. This method requires sufficient mydriasis to see the marks on the IOL optic. An obvious limitation in accuracy is the 10-degree steps on the slit-lamp's measuring reticule.

Errors produced by some combination of misalignment or incorrect toric IOL power can be evaluated using the postoperative astigmatic refraction and keratometry value ${ }^{(57)}$, postoperative astigmatic refraction and power and axis of the toric IOL (Figure 4) ${ }^{(49)}$ or wavefront aberrometry ${ }^{(58)}$. Using vector analysis, postoperative residual refractive astigmatism and keratometry can be used to calculate the angle of lens misalignment. This angle is the angle between the target astigmatism vector and the surgically-induced astigmatism vector (vector of the astigmatism achieved after surgery) ${ }^{(57)}$. Vector analysis can also be used to calculate the angle of lens misalignment based on postoperative astigmatic refraction, and power and axis of toric $\mathrm{IOL}^{(49)}$. An online calculator is available for this approach: Berdahl \& Hardten Toric IOL Calculator (www.astigmatismfix.com) ${ }^{(59)}$. Another method for determining lens misalignment is wavefront aberrometry. Based on the internal ocular aberrations, it determines the orientation of the toric $1 \mathrm{~L}$, without requiring a dilated pupi|(58). Note that all of these methods determine the misalignment of the $\mathrm{IOL}$ from an ideal orientation, which may not be the same as the surgically planned orientation due to errors in measuring preoperative corneal astigmatism and the corneal astigmatism induced by the surgery.

There are at least three causes of toric IOL misalignment. One is inaccurate prediction of the ideal IOL alignment, as noted above. A second cause is inaccurate alignment during surgery. Hence, the eye marking procedure is a key factor to achieve correct lens position.

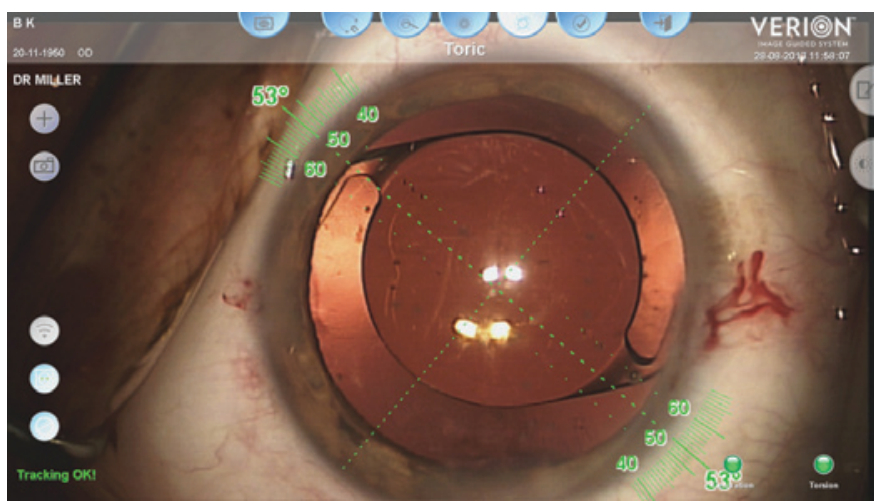

Figure 3. A screenshot of the VERION Digital Marker showing an overlay of the intended toric intraocular lens axis with adjacent limbal protractor on a live view of the patient's eye.
A promising new technology to evaluate toric IOL alignment is intraoperative wavefront aberrometry. The WaveTec Vision Systems (Aliso Viejo, CA) first introduced the intraoperative wavefront aberrometer called ORange, and then substituted it by the Optiwave Refractive Analysis (ORA) system. The aberrometer is directly attached to the operating microscope and is connected to a monitor. After cataract extraction, it measures the aphakic refraction, and suggests a lens power and the axis of toric IOL alignment. After toric lens placement, it detects the need for IOL rotation (Figure 5). Another intraoperative aberrometer that was recently developed is the Holos (Clarity Medical Systems, Pleasanton, California), which provides a continuous video readout of the refractive data during surgery. Unfortunately, intraoperative wavefront aberrometry is still influenced by several factors, such as eyelid speculum pressure and corneal hydration. However, it is a promising technology that can play an important role in toric IOL calculation and alignment.

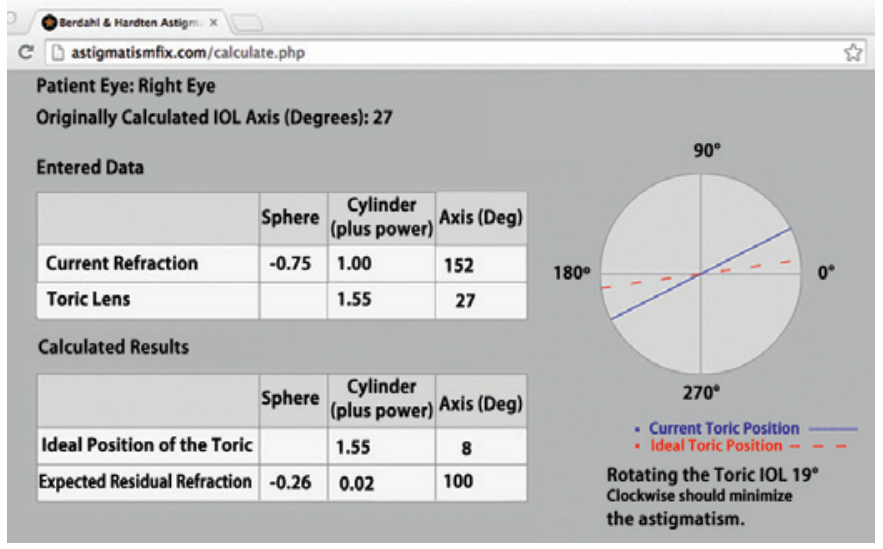

Figure 4. An example of an online vector analysis calculator (Berdahl \& Hardten Toric IOL Calculator [www.astigmatismfix.com] $)^{49}$ that determines at which axis a toric intraocular lens $(\mathrm{IOL})$ should be aligned to minimize the postoperative residual refractive astigmatism. In this case, the vector analysis is based on the patient's postoperative astigmatic refraction and power and axis of the implanted toric IOL. By rotating the toric IOL from the $27^{\circ}$ axis to the $8^{\circ}$ axis, the residual astigmatism would decrease from 1.00 diopter (D) $\times 52^{\circ}$ to $0.02 \mathrm{D} \times 100^{\circ}$.

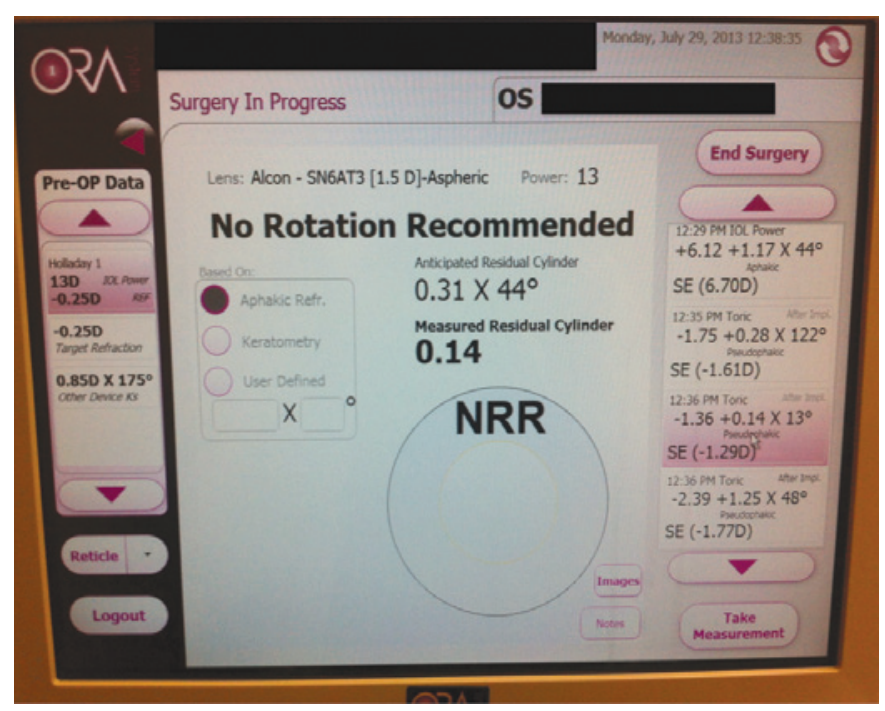

Figure 5. Screen of the Optiwave Refractive Analysis (ORA) system showing the results of a pseudophakic measurement. The anticipated residual cylinder with the specified toric IOL power and meridian of alignment was 0.31 diopter $(D) \times 44^{\circ}$. The residual cylinder measured after lens placement and alignment was of $0.14 \mathrm{D} \times 13^{\circ}$, and the device suggested no rotation of the lens. 
A third cause of $\mathrm{OL}$ misalignment is postoperative rotation, which presumably is influenced by the IOL's architecture and biomaterial and/or ocular anatomy. After lens implantation, the fusion of the anterior and posterior capsules with the lens haptics and border of the optic play an important role in preventing $I O L$ rotation ${ }^{(60)}$. Thus, we would expect that it would be helpful for the anterior capsulorhe$x$ is to be smaller than the diameter of the lens' optic to provide a $360^{\circ}$-overlap. The strength of $\mathrm{IOL}$ adhesion to the bag varies: hydrophobic acrylic IOLs have the highest adhesive properties, followed by the hydrophilic acrylic IOLs, then the PMMA IOLs, and, finally, the silicone $\mathrm{IOLs}^{(61)}$. It is estimated that hydrophobic acrylic lenses rotate less than $1^{\circ}$ postoperatively ${ }^{(27)}$. In addition, the lens design also influences its postoperative rotation. IOLs with smaller diameters misalign more frequently ${ }^{(62)}$. Silicone IOLs with loop haptics have a higher incidence of rotation than those with plate haptics ${ }^{(63)}$, but there are reports of more than $5^{\circ}$ of rotation in over $27 \%$ of silicone plate-haptic lenses ${ }^{(64)}$. One study found that acrylic plate- and loop-haptic lenses have similar rotational stability ${ }^{(65)}$. Another factor associated with postoperative toric IOL rotation is axial myopia. Presumably, the capsular bag is larger in axial myopes, slightly increasing the risk of $\mathrm{IOL}$ rotation.

Realignment of a significantly misaligned toric IOL should be done within the first few weeks of surgery, because the adhesions that form between the capsular bag and the lens can pose difficulties to the second intervention ${ }^{(66)}$. When the $\mathrm{IOL}$ is correctly aligned but there is still residual astigmatism, a corneal relaxing incision or laser refractive surgery can be done.

Other complications associated with toric IOL implantation are those related to the cataract surgery itself, such as posterior capsule opacification, cystoid macular edema, and retinal detachment. Regarding toric phakic IOLs, possible complications include cataract, significant loss of endothelial cells, pupil ovalization, and pupillary block glaucoma ${ }^{(17)}$.

\section{CONCLUSION}

Toric IOLs are an effective and safe tool to treat corneal astigmatism in patients who undergo cataract surgery. However, patients' outcomes depend on accurate corneal astigmatism measurement, accurate marking of corneal meridians and angle of alignment, and accurate and stable $\mathrm{IOL}$ alignment.

\section{REFERENCES}

1. Hoffmann PC, Hutz WW. Analysis of biometry and prevalence data for corneal astigmatism in 23,239 eyes. J Cataract Refract Surg. 2010;36(9):1479-85.

2. Ferrer-Blasco T, Montés-Micó R, Peixoto-de-Matos SC, González-Méijome JM, Cerviño A. Prevalence of corneal astigmatism before cataract surgery. J Cataract Refract Surg. 2009;35(1):70-5.

3. Holland E, Lane S, Horn JD, Ernest P, Arleo R, Miller KM. The AcrySof Toric intraocular lens in subjects with cataracts and corneal astigmatism: a randomized, subject-masked, parallel-group, 1-year study. Ophthalmology. 2010;117(11):2104-11.

4. Entabi M, Harman F, Lee N, Bloom PA. Injectable 1-piece hydrophilic acrylic toric intraocular lens for cataract surgery: efficacy and stability. J Cataract Refract Surg. 2011;37(2):235-40.

5. Cervantes-Coste G, Garcia-Ramirez L, Mendoza-Schuster E, Velasco-Barona C. High-cylinder acrylic toric intraocular lenses: a case series of eyes with cataracts and large amounts of corneal astigmatism. J Refract Surg. 2012;28(4):302-4.

6. Mingo-Botín D, Muñoz-Negrete FJ, Won Kim HR, Morcillo-Laiz R, Rebolleda G, Oblanca N. Comparison of toric intraocular lenses and peripheral corneal relaxing incisions to treat astigmatism during cataract surgery. J Cataract Refract Surg. 2010;36(10):1700-8.

7. Ahmed, II, Rocha G, Slomovic AR, Climenhaga H, Gohill J, Grégoire A, et al. Visual function and patient experience after bilateral implantation of toric intraocular lenses. J Cataract Refract Surg. 2010;36(4):609-16.

8. Lane SS, Ernest P, Miller KM, Hileman KS, Harris B, Waycaster CR. Comparison of clinical and patient-reported outcomes with bilateral AcrySof toric or spherical control intraocular lenses. J Refract Surg. 2009;25(10):899-901.

9. Dick HB, Krummenauer F, Tröber L. [Compensation of corneal astigmatism with toric intraocular lens: results of a multicentre study]. Klin Monbl Augenheilkd. 2006;223(7): 593-608. German.
10. Lichtinger A, Sandstedt CA, Schwartz DM, Chayet AS. Correction of astigmatism after cataract surgery using the light adjustable lens: a 1-year follow-up pilot study. J Refract Surg. 2011;27(9):639-42

11. Jaimes M, Xacur-García F, Alvarez-Melloni D, Graue-Hernández EO, Ramirez-Luquin T, Navas A. Refractive lens exchange with toric intraocular lenses in keratoconus. Refract Surg. 2011;27(9):658-64.

12. Visser N, Gast ST, Bauer NJ, Nuijts RM. Cataract surgery with toric intraocular lens implantation in keratoconus: a case report. Cornea. 2011;30(6):720-3.

13. Navas A, Suárez R. One-year follow-up of toric intraocular lens implantation in forme fruste keratoconus. J Cataract Refract Surg. 2009:35(11):2024-7.

14. Venter J, Pelouskova M. Outcomes and complications of a multifocal toric intraocular lens with a surface-embedded near section. J Cataract Refract Surg. 2013;39(6):859-66.

15. Ferreira TB, Marques EF, Rodrigues A, Montés-Micó R. Visual and optical outcomes of a diffractive multifocal toric intraocular lens. J Cataract Refract Surg. 2013;39(7):1029-35.

16. Visser N, Nuijts RM, de Vries NE, Bauer NJ. Visual outcomes and patient satisfaction after cataract surgery with toric multifocal intraocular lens implantation. J Cataract Refract Surg. 2011;37(11):2034-42.

17. Muñoz G, Cardoner A, Albarrán-Diego C, Ferrer-Blasco T, Belda-Salmeron L. Iris-fixated toric phakic intraocular lens for myopic astigmatism. J Cataract Refract Surg. 2012;38(7): 1166-75.

18. Doors M, Budo CJ, Christiaans BJ, Luger M, Marinho AA, Dick HB, et al. Artiflex Toric foldable phakic intraocular lens: short-term results of a prospective European multicenter study. Am J Ophthalmol. 2012;154(4):730-9 e2.

19. Crema AS, Walsh A, Ventura BV, Santhiago MR. Visual outcomes of eyes implanted with the new toric multifocal intraocular lens. J Refract Surg. 2014; in press.

20. Althomali TA. Posterior chamber toric phakic IOL implantation for the management of pediatric anisometropic amblyopia. J Refract Surg. 2013;29(6):396-400.

21. Ryan A, Hartnett C, Lanigan B, O'Keefe M. Foldable iris-fixated intraocular lens implantation in children. Acta ophthalmol. 2012;90(6):e458-62.

22. Sedaghat M, Ansari-Astaneh MR, Zarei-Ghanavati M, Davis SW, Sikder S. Artisan iris-supported phakic IOL implantation in patients with keratoconus: a review of 16 eyes. Refract Surg. 2011;27(7):489-93.

23. Nanavaty MA, Lake DB, Daya SM. Outcomes of pseudophakic toric intraocular lens implantation in Keratoconic eyes with cataract. J Refract Surg. 2012;28(12):884-9.

24. Luck J. Customized ultra-high-power toric intraocular lens implantation for pellucid marginal degeneration and cataract. J Cataract Refract Surg. 2010;36(7):1235-8

25. Stewart CM, MCAlister JC. Comparison of grafted and non-grafted patients with corneal astigmatism undergoing cataract extraction with a toric intraocular lens implant. Clin Experiment Ophthalmol. 2010;38(8):747-57.

26. Hayashi K, Manabe S, Yoshida M, Hayashi H. Effect of astigmatism on visual acuity in eyes with a diffractive multifocal intraocular lens. J Cataract Refract Surg. 2010;36(8): $1323-9$

27. Visser N, Bauer NJ, Nuijts RM. Toric intraocular lenses: historical overview, patient selection, IOL calculation, surgical techniques, clinical outcomes, and complications. J Cataract Refract Surg. 2013;39(4):624-37.

28. Shirayama M, Wang L, Weikert MP, Koch DD. Comparison of corneal powers obtained from 4 different devices. Am J Ophthalmol. 2009;148(4):528-35 e1.

29. Kobashi H, Kamiya K, Igarashi A, Ishii R, Sato N, Wang G, et al. Comparison of corneal power, corneal astigmatism, and axis location in normal eyes obtained from an autokeratometer and a corneal topographer. J Cataract Refract Surg. 2012;38(4):648-54.

30. Visser N, Berendschot TT, Verbakel F, de Brabander J, Nuijts RM. Comparability and repeatability of corneal astigmatism measurements using different measurement technologies. J Cataract Refract Surg. 2012;38(10):1764-70.

31. Srivannaboon S, Soeharnila, Chirapapaisan C, Chonpimai P. Comparison of cornea astigmatism and axis location in cataract patients measured by total corneal power, automated keratometry, and simulated keratometry. J Cataract Refract Surg. 2012; 38(12):2088-93

32. Wang L, Mahmoud AM, Anderson BL, Koch DD, Roberts CJ. Total corneal power estimation: ray tracing method versus gaussian optics formula. Invest Ophthalmol Vis Sci. 2011;52(3):1716-22

33. Koch DD, Ali SF, Weikert MP, Shirayama M, Jenkins R, Wang L. Contribution of posterior corneal astigmatism to total corneal astigmatism. J Cataract Refract Surg. 2012; 38(12):2080-7

34. Ho JD, Tsai CY, Tsai RJ, Kuo LL, Tsai IL, Liou SW. Validity of the keratometric index: evaluation by the Pentacam rotating Scheimpflug camera. J Cataract Refract Surg. 2008;34(1):137-45

35. Koch DD, Jenkins R, Weikert MP, Yeu E, Wang L. Correcting astigmatism with toric intraocular lenses: the effect of posterior corneal astigmatism. J Cataract Refract Surg. 2013;39(12):1803-9.

36. Visser N, Berendschot TT, Bauer NJ, Nuijts RM. Vector analysis of corneal and refractive astigmatism changes following toric pseudophakic and toric phakic IOL implantation. Invest Ophthalmol Vis Sci. 2012;53(4):1865-73.

37 Koch PS. Structural analysis of cataract incision construction. J Cataract Refract Surg. 1991;17:661-7.

38. Vass C, Menapace R, Rainer G. Corneal topographic changes after frown and straight sclerocorneal incisions. J Cataract Refract Surg. 1997;23(6):913-22.

39. Wollensak J, Pham DT, Seiler T. [Effect of incision form and tunnel length on induced astigmatism with the no-stitch technique.] Ophthalmologe. 1994:91(4):439-41. German. 
40. Altan-Yaycioglu R, Akova YA, Akca S, Gur S, Oktem C. Effect on astigmatism of the location of clear corneal incision in phacoemulsification of cataract. J Refract Surg. 2007;23(5):515-8.

41. Mallik VK, Kumar S, Kamboj R, Jain C, Jain K, Kumar S. Comparison of astigmatism following manual small incision cataract surgery: superior versus temporal approach. Nepal J Ophthalmol. 2012;4(1):54-8.

42. Pakravan M, Nikkhah H, Yazdani S, Shahabi C, Sedigh-Rahimabadi M. Astigmatic outcomes of temporal versus nasal clear corneal phacoemulsification. J Ophthalmic Vis Res. 2009;4(2):79-83.

43. Anders N, Pham DT, Antoni HJ, Wollensak J. Postoperative astigmatism and relative strength of tunnel incisions: a prospective clinical trial. J Cataract Refract Surg. 1997; 23(3):332-6.

44. Holladay JT, Moran JR, Kezirian GM. Analysis of aggregate surgically induced refractive change, prediction error, and intraocular astigmatism. J Cataract Refract Surg. 2001 27(1):61-79.

45. East Valley Ophthalmology. [Internet]. IOL power calculations: surgically induced astigmatism calculator. [cited 2014 Jan 5]. Available from: http://www.doctor-hill.com/.

46. Langenbucher A, Viestenz A, Szentmary N, Behrens-Baumann W, Viestenz A. Toric intraocular lenses--theory, matrix calculations, and clinical practice. J Refract Surg. 2009;25(7):611-22

47. Tecnis. Toric aspheric IOL. [Internet]. Tecnis toric calculator. [cited 2014 Jan 5]. Available from: http://www.tecnistoriciol.com/tecnis-toric-iol-calculator/.

48. Hayashi K, Hirata A, Manabe S, Hayashi H. Long-term change in corneal astigmatism after sutureless cataract surgery. Am J Ophthalmol. 2011;151(5):858-65.

49. Ma JJ, Tseng SS. Simple method for accurate alignment in toric phakic and aphakic intraocular lens implantation. J Cataract Refract Surg. 2008:34(10):1631-6.

50. Chang J. Cyclotorsion during laser in situ keratomileusis. J Cataract Refract Surg. 2008 34(10):1720-6

51. Febbraro JL, Koch DD, Khan HN, Saad A, Gatinel D. Detection of static cyclotorsion and compensation for dynamic cyclotorsion in laser in situ keratomileusis. J Cataract Refract Surg. 2010;36(10):1718-23.

52. Popp N, Hirnschall N, Maedel S, Findl O. Evaluation of 4 corneal astigmatic marking methods. J Cataract Refract Surg. 2012;38(12):2094-9.

53. Cha D, Kang SY, Kim SH, Song JS, Kim HM. New axis-marking method for a toric intraocular lens: mapping method. J Refract Surg. 2011;27(5):375-9.
54. Osher RH. Iris fingerprinting: new method for improving accuracy in toric lens orientation. J Cataract Refract Surg. 2010;36(2):351-2

55. Hill WE, Lackerbauer C, Olsen T, Shah S. Diagnostic technologies for enhanced cataract surgery outcomes: surgeons discuss their preferred tools for achieving superior results. Cataract \& Refractive Surgery Today Europe [Internet]. 2013 mar [cited 2014 Jan 5];20-7. Available from: http://bmctoday.net/crstodayeurope/pdfs/0313CRSTEuro_bf3_ Diagnostics.pdf

56. Villegas EA, Alcón E, Artal P. Minimum amount of astigmatism that should be corrected. J Cataract Refract Surg. 2014;40(1):13-9.

57. Alpins NA, Goggin M. Practical astigmatism analysis for refractive outcomes in cataract and refractive surgery. Surv Ophthalmol. 2004;49(1):109-22.

58. Carey PJ, Leccisotti A, McGilligan VE, Goodall EA, Moore CB. Assessment of toric intraocular lens alignment by a refractive power/corneal analyzer system and slit lamp observation. J Cataract Refract Surg. 2010;36(2):222-9.

59. Toric results analyzer. [Internet]. [cited 2014 Jan 5]. Available from: http://www.astigmatismfix.com

60. Linnola RJ, Werner L, Pandey SK, Escobar-Gomez M, Znoiko SL, Apple DJ. Adhesion of fibronectin, vitronectin, laminin, and collagen type IV to intraocular lens materials in pseudophakic human autopsy eyes. Part 1: histological sections. J Cataract Refract Surg. 2000;26(12):1792-806.

61. Lombardo M, Carbone G, Lombardo G, De Santo MP, Barberi R. Analysis of intraocular lens surface adhesiveness by atomic force microscopy. J Cataract Refract Surg. 2009;35(7):1266-72

62. Chang DF. Early rotational stability of the longer Staar toric intraocular lens: fifty consecutive cases. J Cataract Refract Surg. 2003;29(5):935-40.

63. Patel CK, Ormonde S, Rosen PH, Bron AJ. Postoperative intraocular lens rotation: a randomized comparison of plate and loop haptic implants. Ophthalmology. 1999; 106(11):2190-5; discussion 2196

64. Chang DF. Comparative rotational stability of single-piece open-loop acrylic and plate-haptic silicone toric intraocular lenses. J Cataract Refract Surg. 2008;34(11):1842-7.

65. Prinz A, Neumayer T, Buehl W, Vock L, Menapace R, Findl O, et al. Rotational stability and posterior capsule opacification of a plate-haptic and an open-loop-haptic intraocular lens. J Cataract Refract Surg. 2011;37(2):251-7.

66. Chang DF. Repositioning technique and rate for toric intraocular lenses. J Cataract Refract Surg. 2009;35(7):1315-6.

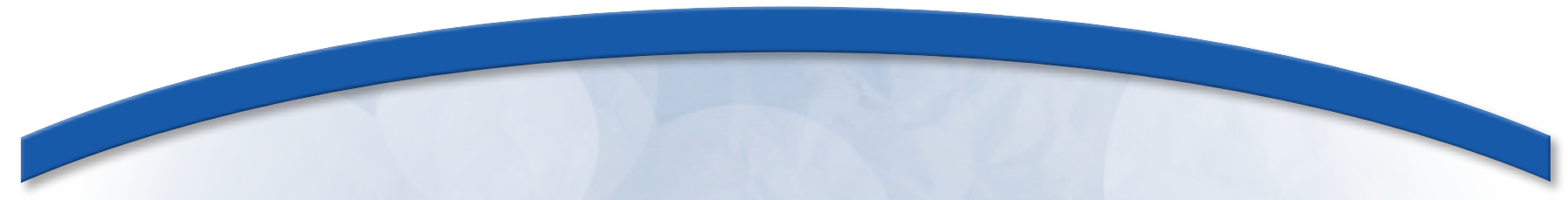

VII Congresso Brasileiro da SOBLEC

\author{
10 a 12 de março de 2015 \\ Maksoud Plaza Hotel \\ São Paulo - SP
}

Informações:

E-mail: atendimento3@creativesolution.com.br

Site: www.congressosoblec.com.br

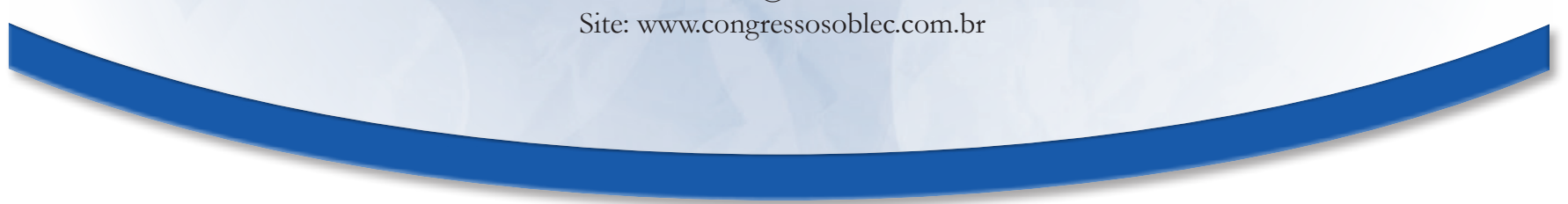

